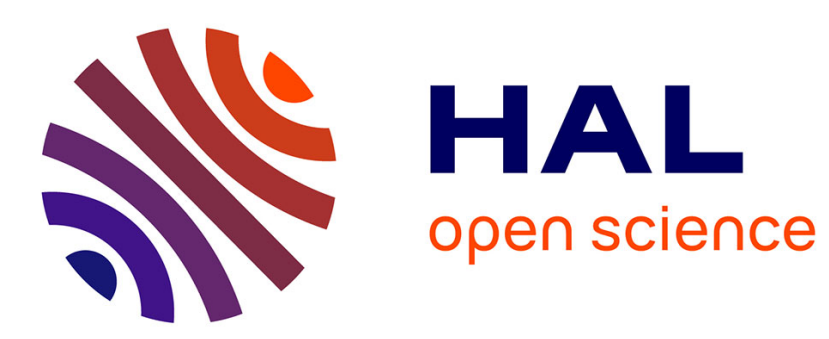

\title{
ULTRA-THIN SEMICONDUCTOR QUANTUM WELLS : POTENTIAL SHAPES AND STRAIN EFFECTS
}

C. Priester, G. Allan, M. Lannoo

\section{> To cite this version:}

C. Priester, G. Allan, M. Lannoo. ULTRA-THIN SEMICONDUCTOR QUANTUM WELLS: POTENTIAL SHAPES AND STRAIN EFFECTS. Journal de Physique Colloques, 1987, 48 (C5), pp.C5203-C5-206. 10.1051/jphyscol:1987541 . jpa-00226745

HAL Id: jpa-00226745

https://hal.science/jpa-00226745

Submitted on 1 Jan 1987

HAL is a multi-disciplinary open access archive for the deposit and dissemination of scientific research documents, whether they are published or not. The documents may come from teaching and research institutions in France or abroad, or from public or private research centers.
L'archive ouverte pluridisciplinaire HAL, est destinée au dépôt et à la diffusion de documents scientifiques de niveau recherche, publiés ou non, émanant des établissements d'enseignement et de recherche français ou étrangers, des laboratoires publics ou privés. 


\title{
ULTRA-THIN SEMICONDUCTOR QUANTUM WELLS : POTENTIAL SHAPES AND STRAIN EFFECT'S
}

\author{
C. PRIESTER, G, ALLAN and M. LANNOO \\ Laboratoire d'Etudes des Surfaces et Interfaces, CNRS-UA 253. \\ Institut Supérieur d'Electronique du Nord, 41, Bd Vauban, \\ F-59046 Lille Cedex, France
}

Résumé. - La forme du potentiel dans un puits quantique très étroit (de un à séize plans atomiques) est calculee dans $I^{\prime a p p r o x i m a t i o n ~ d e s ~ l i a i s o n s ~ f o r t e s . ~ U n ~ m o d e ̀ l e ~ d e ~}$ charges ponctuelles (ajusté sur les variations de la constante diélectrique de volume en fonction de la longueur d'onde) permet d'obtenir de manière autocohérente le potentiel résultant des transferts de charge au voisinage des interfaces. Dans les systèmes non contraints (GaAs/AlAs/GaAs, CdTe/HgTe/CdTe), la profondeur du puits est égale à la discontinuité de bandes de $l^{\prime}$ hétérojonction dès que le puits contient plus de quatre plans atomiques. De plus on a commutativité c'est-à-dire que le potentiel pour un système $A / B / A$ est exactement l'opposé de celui du système B/A/B. Par contre dans les puits contraints (constitués de ZnTe et CaTe ou de ZnTe et HgTe), la profondeur du puits se stabilise seulement a partir des puits de plus de huit plans, et il n'y a plus commutativité.

Abstract. - In the tight-binding approximation, we calculate the potential shape of an ultra-thin (one to sixteen layers) semiconductor quantum well. The potential due to charge transfers near the heterojunctions is calculated self- consistently using a point charge approximation which is fitted to reproduce the bulk dielectric constant variations with wavelength. For unstrained systems like (AlAs/GaAs/AlAs or $\mathrm{HgTe} / \mathrm{CdTe} / \mathrm{HgTe}$ ) the well depth is equal to the isolated heterojunction band offset as soon as the well width is larger than four planes. Moreover, these systems are commutative (A/B/A potential is exactly opposite to the B/A/B one). But for strained wells (like ZnTe/CdTe/ZnTe, ZnTe/HgTe/ZnTe, CdTe/ZnTe/CdTe or HgTe/ZnTe/HgTe, the isolated heterojunction band offset is obtained for wells wider than 8 planes and commutativity is no longer satisfied.

\section{Introduction.}

In the effective mass approximation a semiconductor quantum well is usually treated as a potential square well whose depth is equal to the heterojunction band offset [1]. For broad wells, this is certainly a good approximation. For thin wells, a slight modification of the potential shape, depth or width affects the quantum well energy levels. We then consider ultra-thin (1 to 8 cation planes in the well) quantum welis. When the semiconductor bulk parameters are different, we assume that a semiconductor $\mathrm{B}$ deposited on a thick substrate made with semiconductor $A$, takes an in-plane parameter equal to the $A$ one and that the interplane distance is modified according to classical elasticity. The strain effect can be separated in a variation of the charge transfers near the heterojunctions and a shift of the bands.

In section II, we briefly describe the model we use. It is an extension of previous works [2,3] for isolated heterojunctions. In order to avoid the problem of tight-binding parameters we have only considered common anion systems. The potential and the charge transfers are self-consistently calculated. In section III, application is made to GaAl/AlAs, CdTe/HgTe, CdTe/ZnTe and HgTe/ZnTe systems. For the II-VI compounds heterojunctions, we compare our results with recent experimental work [4]. We notably show that the strain suppresses the band offset commutativity. 


\section{Theory}

2.1 UNSTRAINED QUANTUM WELLS. - The quantum well $\mathrm{A} / \mathrm{B} / \mathrm{A}$ is made of a few (N)[100] cation planes of semiconductor $B$ substituted to $N$ consecutive [100]) cation planes of an infinite $A$ semiconductor. $A$ and $B$ have a common anion (like As or $\mathrm{Te}$ ). The bulk semiconductor band structures are described in the tight-binding approximation using a sp $\mathrm{s}^{*}$ basis set [5]. Spin orbit coupling is also included. Charge transfers are treated self consistently in a point charge model which reproduces fairly well the bulk dielectric constant variation with wavelength. This allows to calculate bulk dipole layers and to align the free atom energy levels of the common anion. Such an approach is necessary as any heterojunction dipole layer is screened by the long wavelength dielectric constant $\epsilon$. A more detailed study of the screening near an heterojunction will be the subject of a forthcoming publication. As both semiconductors have a common anion, we avoid any problem connected to tight-binding parameter evaluation near the heterojunction [2].

2.2 STRAINED QUANTUM WELLS. - When a few planes of semiconductor B (whose bulk lattice parameter is $b)$ are sandwidched between two infinite slabs made with semiconductor A (where bulk parameter is a), we assume that the lattice parameter in the layer plane will be in the whole system equal to a. We neglect any relaxation effect near the heterojunctions. All distances $b_{\perp}$ between [100] planes in the well are equal and given by classical elasticity [6]

$$
\frac{b_{\perp}-b}{b}=-2 \frac{c_{12}}{c_{11}} \frac{a-b}{b}
$$

This variation of the interatomic distances changes the tight-binding parameters. For the interatomic ones, we have taken the usual $\mathrm{d}^{-2}$ Harrisson law. This gives reasonable agreement for the variation of gap with pressure [7]. This has two effects :

- the B semiconductor valence band is modified. Compared to the value of the band offsets, this effect is not always negligible (Table 1).

The charge transfers near the heterojunction are also modified and this affects the dipole layer.

3. Results

3.1 UNSTRAINED SYSTEMS : GaAs/A1As and HgTe/CdTe.

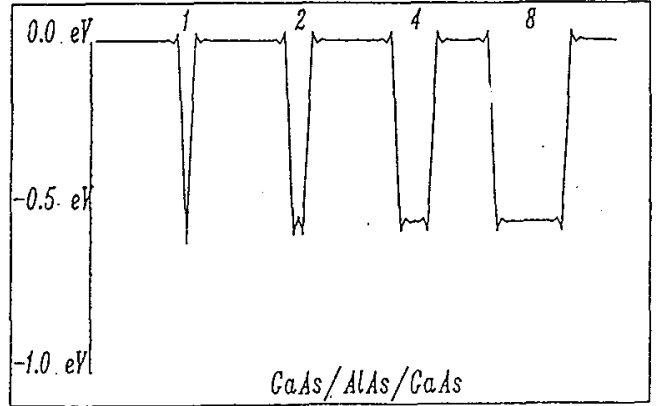

(a)

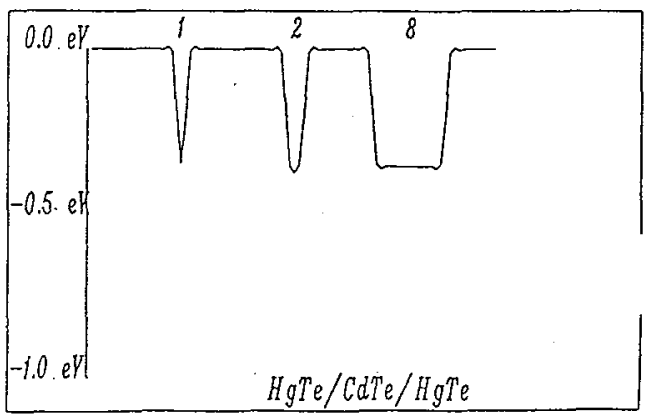

(b)

Figure I : Top of valence band across the welt for GaAs/AlAs/Gais ane HeTe/CaTe/HgTe systems. The numbers are the numbers of cation planes insiae the weit. 
On figure 1, we have plotted the top of valence band for GaAs/AlAs/GaAs (a) and $\mathrm{HgTe} / \mathrm{CdTe} / \mathrm{HgTe}$ (b). We see that the isolated band offset is reached as we have $2 \mathrm{~B}$ cations planes. If we calculate the systems AlAs/GaAs/AIAs or CdTe/HgTe/CdTe, we get exactly the opposite result showing that we have commutativity. The valence band offsets we calculate are in good agreement with experimental results $[8,4]$.

3.2. STRAINED SYSTEMS : CdTe/ZnTe and HgTe/ZnTe.

\begin{tabular}{|c|c|c|c|}
\hline B A & HgTe & CaTe & ZnTe \\
\hline HgTe & $\begin{array}{l}0.00 \\
0.00\end{array}$ & -0.01 & -0.14 \\
\hline CaTe & 0.01 & 0.00 & +0.17 \\
& 1.60 & 1.59 & 1.85 \\
\hline ZnTe & 0.48 & 0.50 & 0 \\
2.17 & 2.11 & 2.56 \\
\hline
\end{tabular}

Table 1. - Gap edges for different semiconductors $B$ strained to semiconductor $A$ lattice parameter in the [100]plane (top : valence band, bottom : conduction band). Lattice parameters are respectively 6.461, 6.481 and 6.103 Angströms for HgTe, CaTe and ZnTe.

To calculate the valence band shape, we separate the strain effect on the top of the valence band (Table 1) and on the dipole layer. For instance if we consider $\mathrm{CdTe} / \mathrm{ZnTe} / \mathrm{CdTe}$, we get a dipole layer equal to - $0.67 \mathrm{eV}$ to which we must add a shift of the valence band (Table 1) equal to $+0.50 \mathrm{eV}$. This gives a valence band offset equal to $-.17 \mathrm{eV}$. The same quantities for $\mathrm{ZnTe} / \mathrm{CdTe} / \mathrm{ZnTe}$ are $+0.57 \mathrm{eV}$ and $+0.37 \mathrm{eV}$ which gives a valence band offset of $.94 \mathrm{eV}$. If we assume no strain at the $\mathrm{ZnTe} / \mathrm{CaTe}$ heterojunction, we get a dipole layer equal - $0.41 \mathrm{eV}$ for CaTe/ZnTe/CdTe and $+0.41 \mathrm{eV}$ for $\mathrm{ZnTe} / \mathrm{CdTe} / \mathrm{ZnTe}$. Commutativity is satisfied. But as strains are opposite in the well, the effects on the dipole layer are also opposite giving rise to almost equal absolute values of strained dipole layers. As the origin has always been taken outside the well, we must compare the absolute values. The valence band offsets are quite different even if the dipole layers are very close. On figure 2 , the top of the valence band is plotted across the well. The non commutativity is clear. Not only the amplitudes are different but also the well shape.
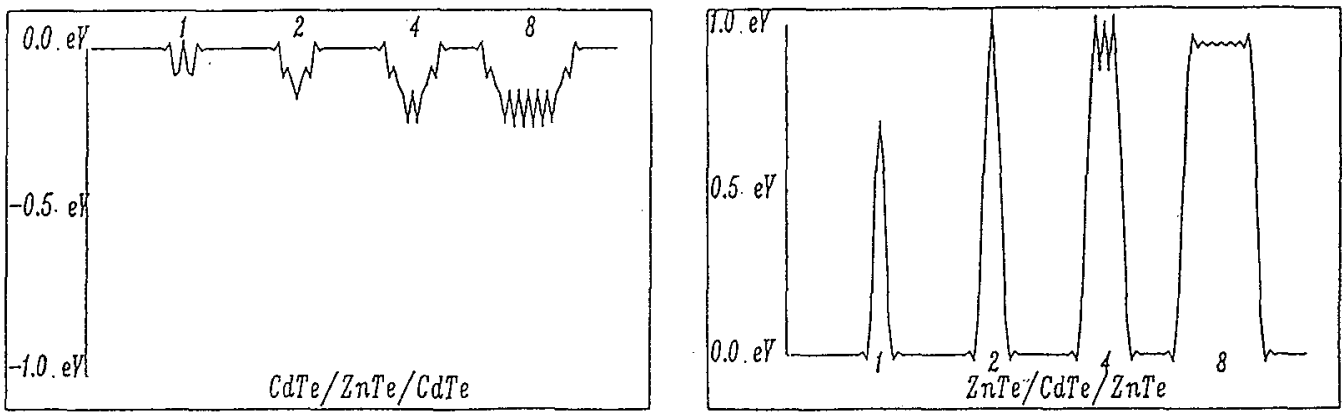

Figure 2 : Top of valence band across the well for CaTe/ZnTe/CaTe and ZnTe/CaTe/2nTe systems. Tha numbers are the numbers of cation planes inside the well. 
Measurements of the core levels near an heterojunction give direct access to the dipole layer or its variations. Recent measurements [4] of the cation core level energy for the CdTe/ZnTe/CdTe and $\mathrm{ZnTe} / \mathrm{CdTe} / \mathrm{ZnTe}$ systems give dipole layer variation equal to $0.17 \mathrm{eV}$ which must be compared to calculated value equal to $0.10 \mathrm{eV}$. The same quantities for $\mathrm{HgTe} / \mathrm{ZnTe}$ are respectively $0.09 \mathrm{eV}$ and $.17 \mathrm{eV}$. The agreement (sign and amplitude) between theory and experiment is quite good.

In conclusion, we have pointed out the influence of strain on the potential shape and valence band offsets. If the absolute values of the dipole layer are not very different, the strain generally shifts upwards the top of the valence band (except for HgTe) breaking the commutativity in multiple heterojunction systems.

\section{References}

[1] See for example M. ALTARELLI in "Heterojunctions and Semiconductor Superlattice, Proceedings of the Winter School, Les Houches, March 1985, G. Allan, G. Bastard, N. Boccara, M. Lannoo and M. Voos ed., Springer Verlag, p.12

[2] B. HAUSSY, C. PRIESTER, G. ALLAN and M. LANNOO, Phys. Rev. B36 (publication scheduled for $15 \mathrm{July} 1987$ ).

[3] A. MUNOZ, J.C. DURAN and F. FLORES, Phys. Rev. B35, , 1987.

[4] TRAN MINH DUC, C. HSU and J.P. FAURIE, Phys. Rev. Lett. 58,1129 (1987) concerns the (111) system, but an unpublished work by these authors concerns the (100) system.

[5] GaAs, AlAs, ZnTe bulk parameters are corrected values from P. VoGL, M.P. HJALMARSON and J.D. DOW, J. Chem. Solids, 44,365 (1983). For CdTe and HgTe, we use A. Kobayashi, O.F. Sankey and J.D. Dow, Phys. Rev. B25, 6367 (1982), including spin orbit coupling.

[6] J.Y. MARZIN, ibid. ref. [1], p. 161 .

[7] G. MARTINEZ, in Handbook on Semiconductors, V.2, M. Balkanski ed., North Holland (1980), p. 181 .

[8] Recent measurements of GaAs/A1As offsets give $.49 \mathrm{eV}$ [W.I. WANG, T.S. KUAN, E.E. MENDEZ and L. ESAKI, Phys. Rev. B31, 6890 (1985)], .45 eV [M. HEIBLUN, M.I. NATHAN and M. EIZENBERG, Appl. Phys. Lett., 47, 503 (1985)], .55 eV [J. BATEY and S.L. WRIGHT, J. Appl. Phys., 59, $200(1 \overline{986})]$ and $.54 \mathrm{eV}$ [P. DAWSON, B.A. WILSON, C.W. TU and R.C. MILLER, Appl. Phys. Lett., 48, 541 (1986)], and .53 eV [Danan et al., Phys. Rev. B35, 6207 (1987)]. 